\title{
CUSTOS E RENTABILIDADE DO MILHO EM FUNÇÃO DO MANEJO DO SOLO E DA ADUBAÇÃO NITROGENADA ${ }^{1}$
}

\author{
Flávio Hiroshi Kaneko², Orivaldo Arf ${ }^{3}$, Douglas de Castilho Gitti ${ }^{3}$, \\ Maria Aparecida Anselmo Tarsitano ${ }^{3}$, Rosalina Maria Alves Rapassi ${ }^{3}$, Rafael Gonçalves Vilela ${ }^{3}$
}

\section{ABSTRACT \\ MAIZE COSTS AND PROFITABILITY ACCORDING TO SOIL MANAGEMENT AND NITROGEN FERTILIZATION}

Agronomic practices that help farmers to raise yield and reduce costs must be studied to ensure agricultural sustainability. Thus, the objective of this study was to analyze economically the effect of soil management and nitrogen fertilization in maize crops. Treatments consisted of a combination of 3 soil management techniques (plow harrows + floating harrows, chisel + floating harrows, and no-tillage), 5 periods of nitrogen fertilization (control - $0 \mathrm{~kg} \mathrm{ha}^{-1} \mathrm{~N} ; 120 \mathrm{~kg} \mathrm{ha}^{-1}$ after sowing (S); $120 \mathrm{~kg} \mathrm{ha}^{-1}$ in the $\mathrm{V}_{6}$ stage; $30 \mathrm{~kg} \mathrm{ha}^{-1}(\mathrm{~S})+90 \mathrm{~kg} \mathrm{ha}^{-1}$ in $\mathrm{V}_{6}$; $30 \mathrm{~kg} \mathrm{ha}^{-1}(\mathrm{~S})+45 \mathrm{~kg} \mathrm{ha}^{-1}$ in $\mathrm{V}_{4}+45 \mathrm{~kg} \mathrm{ha}^{-1}$ in $\mathrm{V}_{8}$. The total operating cost (TOC), gross revenue (GR), operating profit (OP), profitability index (PI), break-even yield, and break-even price were estimated. It was concluded that the no-tillage system, after 11 years of management, associated with nitrogen fertilization promotes positive PI and OP, being useful to farmers.

KEY-WORDS: Zea mays; production cost; no-tillage; conventional tillage.

\section{INTRODUÇÃO}

O milho é um cereal de grande importância para o agronegócio mundial, por ser considerado o principal insumo na fabricação de ração animal. Além disso, atualmente, sua produção vem aumentando, para ser utilizado como matéria-prima na fabricação de etanol, nos Estados Unidos da América.

De acordo com dados da Food and Agriculture Organization (FAO), citados pelo Ministério da Agricultura, Pecuária e Abastecimento (Brasil 2009), o Brasil é o terceiro maior produtor mundial de milho, com 34,9 milhões de toneladas de grãos produzidos, perdendo apenas para a China (135 milhões) e

\section{RESUMO}

Práticas agronômicas que ajudem o agricultor a elevar a produtividade e diminuir os custos de produção devem ser estudadas para garantir a sustentabilidade agrícola. Assim, o objetivo deste trabalho foi analisar, economicamente, o efeito do manejo do solo e do nitrogênio, na cultura do milho. Os tratamentos foram constituídos pela combinação de 3 manejos do solo (grade pesada + grade niveladora, escarificador + grade niveladora e plantio direto) e 5 épocas de aplicação de nitrogênio (testemunha sem N; $120 \mathrm{~kg} \mathrm{ha}^{-1} \operatorname{logo}$ após a semeadura (S); $120 \mathrm{~kg} \mathrm{ha}^{-1}$ no estádio $\mathrm{V}_{6} ; 30 \mathrm{~kg} \mathrm{ha}^{-1}(\mathrm{~S})+90 \mathrm{~kg} \mathrm{ha}^{-1} \mathrm{em} \mathrm{V}_{6}$; $\left.30 \mathrm{~kg} \mathrm{ha}^{-1}(\mathrm{~S})+45 \mathrm{~kg} \mathrm{ha}^{-1} \mathrm{em} \mathrm{V}_{4}+45 \mathrm{~kg} \mathrm{ha}^{-1} \mathrm{em} \mathrm{V}_{8}\right)$. Foram estimados o custo operacional total (COT), receita bruta (RB), lucro operacional (LO), índice de lucratividade (IL), produtividade de equilíbrio e preço de equilíbrio. Conclui-se que o sistema de plantio direto, após 11 anos de manejo, associado à adubação nitrogenada, promoveu LO e IL positivos, sendo favorável o uso destas práticas, pelos agricultores.

PALAVRAS-CHAVE: Zea mays; custo de produção; plantio direto; plantio convencional.

para os Estados Unidos (282 milhões). A produção mundial total deste cereal, no ano de 2007, foi de, aproximadamente, 792 milhões de toneladas de grãos.

Nos últimos anos, a área ocupada com o sistema plantio direto se destacou em importância, chegando, na safra 2004/2005, a quase 96 milhões de hectares, em âmbito mundial, e 25,5 milhões de hectares, no Brasil, na safra 2005/2006 (Febrapdp 2009). Melo Filho (2000), estudando o custo de produção do milho cultivado em SPD e em sistema convencional, concluiu que a despesa com insumos foi maior no SPD. Os custos com as operações agrícolas, entretanto, foram bem maiores no sistema convencional e

1. Trabalho recebido em ago./2009 e aceito para publicação em mar./2010 (nº registro: PAT 6888/ DOI: 10.5216/pat.v40i1.6888).

2. Fundação de Apoio à Pesquisa Agropecuária de Chapadão (Fundação Chapadão), Departamento de Fitotecnia, Socioeconomia e Tecnologia de Alimentos, Chapadão do Sul, MS, Brasil.E-mail: flaviokaneko@fundacaochapadao.com.br.

3. Universidade Estadual Paulista "Júlio de Mesquita Filho", Faculdade de Engenharia de Ilha Solteira, Departamento de Fitotecnia, Socioeconomia e Tecnologia de Alimentos, Ilha Solteira, SP, Brasil.E-mails: arf@agr.feis.unesp.br, gittidouglas@hotmail.com, maat@agr.feis.unesp.br, rosarapassi@itelefonica.com.br, rafal.g.v@hotmail.com. 
o resultado final foi um custo $10,3 \%$ menor no SPD, em relação ao sistema convencional.

A adubação nitrogenada tem papel importante, por ser o $\mathrm{N}$ o nutriente absorvido em maior quantidade pelo milho e, principalmente, pela dificuldade de se avaliar sua disponibilidade no solo, devido às múltiplas reações a que ele está sujeito, mediadas por microorganismos e afetadas por fatores climáticos de difícil previsão (Cantarela \& Duarte 2004).

Figueiredo et al. (2005), trabalhando no Cerrado de Brasília (DF), observaram o efeito de oito tipos de sistemas de manejo do solo, na absorção de nitrogênio pelo milho, e verificaram que os sistemas de manejo (instalados em 1979) influenciam a dinâmica de absorção de nitrogênio pela planta, sendo que, sob o sistema plantio direto e cultivo mínimo com escarificador, houve maior eficiência de recuperação no nitrogênio oriundo do fertilizante, além de maiores teores de $\mathrm{N}$ nos grãos, quando comparado aos manejos com arados de disco e aivecas.

A aplicação de determinada tecnologia influi, diretamente, nos custos de produção e determina, também, a produtividade da lavoura. Dessa forma, é necessário o acompanhamento dos custos que envolvem o sistema de produção, pois, durante levantamento das despesas, é possível identificar tanto elementos responsáveis pelo bom desempenho da lavoura, como os possíveis pontos de estrangulamento do empreendimento agrícola (Vasconcelos et al. 2002).

O objetivo deste trabalho foi avaliar o efeito do manejo do solo e da adubação nitrogenada nos custos de produção e rentabilidade da cultura do milho cultivado em solo anteriormente ocupado por Cerrado.

\section{MATERIAL E MÉTODOS}

A área onde o experimento foi instalado localiza-se no município de Selvíria (MS), na Fazenda de Ensino e Pesquisa e Extensão da Universidade Estadual Paulista, Campus de Ilha Solteira, apresentando coordenadas geográficas próximas a $51^{\circ} 22^{\prime}$ de longitude Oeste e $20^{\circ} 22^{\prime}$ 'de latitude Sul, com altitude de 335 metros. O solo local é do tipo Latossolo vermelho distrófico, textura argilosa (Embrapa 1999). A área experimental faz parte de um experimento de longa duração, sendo que os sistemas de manejo de solo foram implantados na safra 1997/1998.
A cultura foi irrigada com sistema de irrigação por pivô central e o manejo feito com os seguintes coeficientes da cultura $\left(\mathrm{K}_{\mathrm{c}}\right)$ : 0,4 no período de estabelecimento da cultura; 0,8 no período vegetativo; 1,10 na época do florescimento; 0,8 no enchimento de grãos; e 0,5 na maturação.

O delineamento experimental foi o de blocos casualizados, formando fatorial $3 \times 5$, com 15 tratamentos e 4 repetições. Os tratamentos constituíram-se pela combinação de 3 manejos do solo (grade pesada + grade niveladora; escarificador + grade niveladora; e sistema plantio direto) e 5 manejos de adubação nitrogenada (testemunha sem N; $120 \mathrm{~kg} \mathrm{ha}^{-1} \operatorname{logo}$ após a semeadura (S); $120 \mathrm{~kg} \mathrm{ha}^{-1}$ no estádio $\mathrm{V}_{6} ; 30 \mathrm{~kg} \mathrm{ha}^{-1}(\mathrm{~S})+90 \mathrm{~kg} \mathrm{ha}^{-1}$ no estádio $\mathrm{V}_{6}$; $30 \mathrm{~kg} \mathrm{ha}^{-1}(\mathrm{~S})+45 \mathrm{~kg} \mathrm{ha}^{-1}$ no estádio $\mathrm{V}_{4}+45 \mathrm{~kg} \mathrm{ha}^{-1}$ no estádio $\mathrm{V}_{8}$ ).

O manejo do solo com escarificador foi realizado com implemento de 7 hastes, a $35 \mathrm{~cm}$ de profundidade, tracionado por um trator de $150 \mathrm{cv}$ 4x2 TDA (tração dianteira auxiliar). O mesmo trator foi utilizado para tracionar a grade aradora pesada $20 \times 32$ ". A gradagem niveladora foi feita com uma grade 36x20", utilizando-se um trator de $86 \mathrm{cv} 4 \times 2$ TDA. A dessecação da área, bem como as outras pulverizações, foi efetuada com um pulverizador com barra de 12 metros e tanque com capacidade para 600 litros de calda, utilizando-se um trator de $75 \mathrm{cv}$. A semeadura foi realizada com semeadora pneumática de plantio direto, com 4 linhas de $0,90 \mathrm{~m}$, tracionada por um trator de $105 \mathrm{cv} 4 \times 2$ TDA. As operações de adubação nitrogenada foram feitas com adubador de 4 linhas, tracionado com um trator de $75 \mathrm{cv} 4 \times 2$ TDA.

O experimento foi conduzido durante as safras de verão 2007/2008 e 2008/2009. Antes da semeadura da cultura, em ambos os períodos, a área encontrava-se em pousio, no período de inverno. A dessecação da área das parcelas com sistema plantio direto foi realizada com $1.500 \mathrm{~g}_{\text {i.a. }}$ ha $^{-1}$ de glifosato $\left(\right.$ Roundup $\left.^{\circledR}\right)+24 \mathrm{~g}_{\text {ia }}$ ha $^{-1}$ de carfentrazone-ethil $\left(\right.$ Aurora $\left.^{\circledR}\right)$. A semeadura foi realizada mecanicamente, em 01/12/2007 (primeiro ano) e em 21/11/2008 (segundo ano).

A cultivar utilizada, em ambos os períodos de cultivo, foi a AG 8088, híbrido simples de ciclo precoce da Agroceres. As sementes foram tratadas, em ambas as safras, com 52,5 $\mathrm{g}_{\text {i.a }}$ ha $^{-1}$ de imidacloprido + 157,5 $\mathrm{g}_{\text {i.a. }}$ ha $^{-1}$ de thiodicarb $\left(\right.$ Cropstar $\left.^{\mathbb{R}}\right)$, visando ao controle de lagartas do solo, cupins e percevejos. $\mathrm{O}$ 
controle de plantas daninhas, nas duas safras, foi realizado com a aplicação de $1665 \mathrm{~g}_{\mathrm{i} \text {.a }}$ ha $^{-1}$ de metolachlor $+2305 \mathrm{~g}_{\text {i.a. }}$ ha-1 $^{-1}$ de atrazina (Primestra gold ${ }^{\circledR}$ ), aplicados em pré-emergência. Já a lagarta do cartucho foi controlada com 3 aplicações de $129 \mathrm{~g}$ i.a. $\mathrm{ha}^{-1}$ de metomil (Lannate $\left.{ }^{\circledR}\right)+48 \mathrm{~g}_{\text {i.a. }}$ ha $^{-1}$ de triflumuron $\left(\right.$ Certero $\left.^{\circledR}\right)$, em ambos os cultivos.

A adubação de semeadura incluiu a mistura de $350 \mathrm{~kg} \mathrm{ha}^{-1}$ de superfosfato simples e $100 \mathrm{~kg} \mathrm{ha}^{-1} \mathrm{de}$ cloreto de potássio e, para os tratamentos que receberam $\mathrm{N}$, na ocasião da semeadura, acrescentou-se, também, 66,6 $\mathrm{kg} \mathrm{ha}^{-1}$ de ureia.

Para o cálculo de custo de produção, foi utilizada a estrutura do custo operacional total de produção adotada pelo Instituto de Economia Agrícola (IEA), proposta por Matsunaga et al. (1976). O custo operacional efetivo (COE) é composto pelas despesas com operações mecanizadas, operações manuais e materiais consumidos. Se forem acrescentadas ao COE as despesas com encargos financeiros, outras despesas e depreciações, têm-se o custo operacional total (COT).

Os custos foram obtidos com base nos seguintes itens: a) para as operações manuais, foi realizado um levantamento das necessidades de mão-de-obra, nas diversas fases do ciclo produtivo do milho, relacionando, para cada operação realizada, o número de homens/dia (HD) para executá-la, sendo, em seguida, multiplicado o coeficiente técnico de mãode-obra pelo valor médio da região; b) os gastos com materiais foram obtidos mediante o produto entre a quantidade dos materiais usados e os seus respectivos preços de mercado; c) para outras despesas, foi considerada a taxa de 5\% do total das despesas com o COE; d) a despesa com juros de custeio foi obtida considerando-se a taxa de $6,75 \%$ a.a. sobre $50 \%$ do COE; e) a depreciação dos bens de capital fixo foi calculada pelo método linear.

Para determinar a lucratividade dos tratamentos envolvidos, segundo Martin et al. (1997), foram calculadas: a) receita bruta $(\mathrm{RB})(\mathrm{em} \mathrm{R} \$)$, como o produto entre a quantidade produzida (em número de sacos de $60 \mathrm{~kg}$ ) e o preço médio de venda (em R\$); b) lucro operacional (LO), como a diferença entre a receita bruta e o custo operacional total; c) índice de lucratividade (IL), entendido como a proporção da receita bruta que se constitui em recursos disponíveis, após a cobertura do custo operacional total de produção (obtido pela relação entre o lucro operacional e o COT e expresso em porcentagem); d) preço de equilíbrio, dado, em determinado nível de custo ope- racional total de produção, como o preço mínimo a ser obtido para se cobrir este custo, considerando-se a produtividade média do produtor; e) produtividade de equilíbrio, dada, em determinado nível de custo operacional total de produção, como a produtividade mínima para se cobrir este custo, considerando-se o valor médio pago ao produtor.

Os preços médios foram coletados na região, em maio de 2009, e apresentados em reais (R\$).

Neste trabalho, foi feita uma simulação, como se cada tratamento do experimento representasse uma lavoura comercial. Para auxiliar na elaboração dos dados, principalmente em relação ao valor da horamáquina, rendimento das máquinas e preço da saca de milho, foram realizadas entrevistas com produtores de milho da região.

\section{RESULTADOS E DISCUSSÃO}

Para facilitar a análise econômica, os valores das produtividades dos tratamentos foram convertidos em sacas (sc) de 60 quilos de grãos, que é a forma tradicional de comercialização pelos produtores da região. Os valores pagos pelos insumos foram atualizados para o mês de maio de 2009, sendo obtidos em revendas locais. O preço do milho refere-se ao preço médio pago por saca aos produtores da região (R\$ 18,00), em maio de 2009.

$\mathrm{Na}$ Tabela 1, encontra-se a estrutura do custo operacional total (COT) na cultura do milho, no município de Selvíria (MS), sendo o tratamento mais oneroso aquele caracterizado pelo uso do escarificador + niveladora e manejo do $\mathrm{N} \operatorname{com} 30 \mathrm{~N}(\mathrm{~S})+30 \mathrm{~N}$ $\left(\mathrm{V}_{4}\right)+30 \mathrm{~N}\left(\mathrm{~V}_{8}\right)$. Este modelo de estrutura de COT foi utilizado em todos os tratamentos.

Verifica-se, pelos dados da Tabela 1, que os gastos com fertilizantes, seguidos de operações mecanizadas, foram os mais elevados, correspondendo a $32,74 \%$ e $30,91 \%$ do COT, respectivamente. É importante ressaltar que foi considerada a colheita terceirizada do milho, com valor pago correspondendo a 7,5 sc por hectare (valor médio na região).

Os valores referentes ao custo operacional total (COT) dos tratamentos avaliados estão na Tabela 2. O maior valor para o COT refere-se ao tratamento com manejo do solo com escarificador + niveladora e aplicação de $30 \mathrm{~kg} \mathrm{ha}^{-1}$ de $\mathrm{N}$, na ocasião da semeadura, e $45 \mathrm{~kg} \mathrm{ha}^{-1} \mathrm{em} \mathrm{V}_{4}+45 \mathrm{~kg} \mathrm{ha}^{-1} \mathrm{em} \mathrm{V}_{8}$. $\mathrm{O}$ menor valor para o COT corresponde ao manejo do solo com grade pesada + niveladora, sem aplica- 
Tabela 1. Estimativa do custo operacional obtido com a cultura do milho, em função do manejo do solo e da adubação nitrogenada (Selvíria, MS, safras 2007/2008 e 2008/2009).

\begin{tabular}{|c|c|c|c|c|c|c|}
\hline Descrição & Especificação & $\mathrm{n}^{\mathrm{o}}$ vezes & Quantidade & $\begin{array}{l}\text { Valor unitário } \\
(\mathrm{R} \$)\end{array}$ & $\begin{array}{l}\text { Total } \\
\text { (R\$) }\end{array}$ & $\begin{array}{l}\text { Total } \\
\text { (US\$) }\end{array}$ \\
\hline \multicolumn{7}{|l|}{ Operações mecanizadas } \\
\hline Pulverização & HM & 5,00 & 0,15 & 33,10 & 24,83 & 11,82 \\
\hline Escarificação & HM & 1,00 & 0,70 & 73,48 & 51,44 & 24,49 \\
\hline Gradagem niveladora & HM & 1,00 & 0,50 & 36,40 & 18,20 & 8,67 \\
\hline Semeadura e adubação & HM & 1,00 & 0,60 & 48,75 & 29,25 & 13,93 \\
\hline Adubação nitrogenada & HM & 2,00 & 0,80 & 27,20 & 43,52 & 20,72 \\
\hline Irrigaçã̃o & $\mathrm{R} \$ / \mathrm{mm}$ & 1,00 & 150,00 & 2,73 & 409,50 & 195,00 \\
\hline Colheita & - & 1,00 & 7,50 & 18,00 & 135,00 & 64,29 \\
\hline Subtotal & & & & & 711,73 & 338,92 \\
\hline \multicolumn{7}{|l|}{ Operações manuais } \\
\hline Pré-semeadura & HD & 3,00 & 0,10 & 40,00 & 12,00 & 5,71 \\
\hline Semeadura & HD & 3,00 & 0,10 & 40,00 & 12,00 & 5,71 \\
\hline Tratos Culturais & HD & 9,00 & 0,10 & 40,00 & 36,00 & 17,14 \\
\hline $\begin{array}{l}\text { Colheita } \\
\text { Subtotal }\end{array}$ & HD & 1,00 & 0,10 & 40,00 & 4,00 & 1,90 \\
\hline \multicolumn{7}{|l|}{ Material } \\
\hline Superfosfato simples & $\mathrm{t}$ & 1,00 & 0,35 & 980,00 & 343,00 & 163,33 \\
\hline Cloreto de potássio & $\mathrm{t}$ & 1,00 & 0,10 & $1.980,00$ & 198,00 & 94,29 \\
\hline Ureia & $\mathrm{t}$ & 1,00 & 0,27 & 950,00 & 256,50 & 122,14 \\
\hline Glifosato Nortox & 1 & 1,00 & 5,00 & 19,80 & 99,00 & 47,14 \\
\hline Aurora & 1 & 1,00 & 0,06 & 345,00 & 20,70 & 9,86 \\
\hline Cropstar & 1 & 1,00 & 0,35 & 222,00 & 77,70 & 37,00 \\
\hline Sementes AG 8088 & $\mathrm{sc}$ & 1,00 & 1,00 & 240,00 & 240,00 & 114,29 \\
\hline Primestra Gold & 1 & 1,00 & 4,00 & 20,00 & 80,00 & 38,10 \\
\hline Atrazina Siptran & 1 & 1,00 & 2,00 & 9,50 & 19,00 & 9,05 \\
\hline Lannate & 1 & 3,00 & 0,60 & 25,00 & 45,00 & 21,43 \\
\hline Certero & 1 & 3,00 & 0,10 & 172,00 & 51,60 & 24,57 \\
\hline Subtotal & & & & & $1.430,50$ & 681,19 \\
\hline \multicolumn{5}{|c|}{ Custo operacional efetivo (COE) } & $2.206,23$ & $1.050,59$ \\
\hline \multicolumn{5}{|c|}{ Depreciação de máquinas e equipamentos } & 44,58 & 21,23 \\
\hline \multirow{2}{*}{\multicolumn{5}{|c|}{ Outras despesas }} & 110,31 & 52,53 \\
\hline & & \multicolumn{3}{|c|}{ Juros de custeio } & 74,46 & 35,46 \\
\hline \multicolumn{5}{|c|}{ Custo operacional total (COT) } & $2.435,58$ & $1.159,80$ \\
\hline
\end{tabular}

Tabela 2. Custo operacional total (COT) obtido com a cultura do milho, em função do manejo do solo e da adubação nitrogenada (Selvíria, MS, safras 2007/2008 e 2008/2009).

\begin{tabular}{cccc}
\hline \multirow{2}{*}{$\begin{array}{c}\text { Manejo } \\
\text { do solo }\end{array}$} & $\begin{array}{c}\text { Manejo da adubação } \\
\text { nitrogenada }\end{array}$ & $2007 / 2008$ & $2008 / 2009$ \\
\cline { 2 - 4 } & $\mathrm{Sem} \mathrm{N}$ & $2.081,99$ & $2.081,99$ \\
Escarificador + niveladora & $120 \mathrm{~N}(\mathrm{~S})$ & $2.397,78$ & $2.397,78$ \\
& $30 \mathrm{~N}(\mathrm{~S})+90 \mathrm{~N}\left(\mathrm{~V}_{6}\right)$ & $2.397,78$ & $2.397,78$ \\
& $120 \mathrm{~N} \mathrm{~V}\left({ }_{6}\right)$ & $2.397,78$ & $2.397,78$ \\
& $30 \mathrm{~N}(\mathrm{~S})+45 \mathrm{~N}\left(\mathrm{~V}_{4}\right)+45 \mathrm{~N}\left(\mathrm{~V}_{8}\right)$ & $2.435,58$ & $2.435,58$ \\
\hline \multirow{3}{*}{ Grade pesada + niveladora } & $\mathrm{Sem} \mathrm{N}$ & $1.943,73$ & $1.943,73$ \\
& $120 \mathrm{~N}(\mathrm{~S})$ & $2.259,51$ & $2.259,51$ \\
& $30 \mathrm{~N}(\mathrm{~S})+90 \mathrm{~N}\left(\mathrm{~V}_{6}\right)$ & $2.259,51$ & $2.259,51$ \\
& $120 \mathrm{~N} \mathrm{~V}\left(_{6}\right)$ & $2.259,51$ & $2.259,51$ \\
& $30 \mathrm{~N}(\mathrm{~S})+45 \mathrm{~N}\left(\mathrm{~V}_{4}\right)+45 \mathrm{~N}\left(\mathrm{~V}_{8}\right)$ & $2.288,64$ & $2.288,64$ \\
\hline Sistema plantio direto & $\mathrm{Sem} \mathrm{N}$ & $1.982,50$ & $1.982,50$ \\
& $120 \mathrm{~N}(\mathrm{~S})$ & $2.298,29$ & $2.298,29$ \\
& $30 \mathrm{~N}(\mathrm{~S})+90 \mathrm{~N}\left(\mathrm{~V}_{6}\right)$ & $2.298,29$ & $2.298,29$ \\
& $120 \mathrm{~N} \mathrm{~V}\left({ }_{6}\right)$ & $2.298,29$ & $2.298,29$ \\
& $30 \mathrm{~N}(\mathrm{~S})+45 \mathrm{~N}\left(\mathrm{~V}_{4}\right)+45 \mathrm{~N}\left(\mathrm{~V}_{8}\right)$ & $2.336,09$ & $2.336,09$ \\
\hline
\end{tabular}


ção de N. Entretanto, é sempre bom lembrar que as reservas de $\mathrm{N}$ do solo vão se esgotando, à medida em que ocorre a extração do nutriente, caso o mesmo não seja reposto ao solo, comprometendo a produtividade das culturas, ao longo do tempo. Verifica-se que o COT dos tratamentos que receberam todo o adubo nitrogenado, na ocasião da semeadura (120 N (S)), apresentou valor igual aos tratamentos que receberam adubação com $\mathrm{N} \mathrm{em} \mathrm{V}_{6}$. Este fato ocorre porque considerou-se a adubação nitrogenada de $120 \mathrm{~kg} \mathrm{ha}^{-1}$ de N, em uma operação agrícola separada da semeadura (ocorreu na ocasião da semeadura, porém em operação agrícola separada), uma vez que esta dose de N, no sulco de semeadura, poderia afetar a germinação das sementes, considerando-se a fonte de $\mathrm{N}$ utilizada (ureia).

Kaneko et al. (2007), estudando a viabilidade da cultura do milho para a região noroeste paulista, na safra 2006/2007, com manejo do solo com grade pesada + niveladora e manejo do $\mathrm{N}$, sendo um terço da dose total na semeadura e dois terços na fase $\mathrm{V}_{6}$, verificaram COT de $\mathrm{R} \$ 1.357,00$, para uma produtividade de $93 \mathrm{sc} \mathrm{ha}^{-1}$, sendo este valor bem mais baixo que os verificados neste trabalho. Tsunechiro (2008) avaliou o custo de produção e rentabilidade para a cultura do milho cultivado em sistema plantio direto, na safra 2003/2004, para a região de Assis (SP), e concluiu que o custo operacional total (COT) da cultura do milho foi de R $\$ 1.229,86 /$ ha, sendo $36,7 \%$ menor que o COT do tratamento menos oneroso (gra- de pesada + niveladora, sem aplicação de N). Kaneko \& Leal (2010) avaliaram o COT para a cultura do milho, na região dos Chapadões (Chapadão do Sul, MS; Costa Rica, MS; e Chapadão do Céu, GO), para a safra 2009/2010, e observaram que, para esta região, o COT foi de, aproximadamente, R\$2.000,00, com manejo do solo em sistema plantio direto (mais usual na região), sem levar em consideração as despesas com arrendamento (em torno de 10 a 12 sacas de soja por hectare, na região). É importante salientar que as despesas com fertilizantes foram as mais onerosas, correspondendo a $42 \%$ do COT. Para os dados da Tabela 2 (estimativa de COT para o tratamento mais oneroso), o custo com fertilizantes representou $32,7 \%$ do COT, quase $10 \%$ inferior ao determinado por Kaneko \& Leal (2010). Contudo, a expectativa de produtividade para a região dos Chapadões é maior, em relação à região de Selvíria (MS), sendo a quantidade de fertilizantes utilizada nesta região menor que na região dos Chapadões.

As produtividades em sacas $\left(\mathrm{sc} \mathrm{ha}{ }^{-1}\right)$, para a safra 2007/2008 e 2008/2009, estão representadas na Tabela 3. Na primeira safra de cultivo, a maior produtividade foi obtida no tratamento envolvendo o sistema plantio direto e o manejado com $30 \mathrm{~N}(\mathrm{~S})+45 \mathrm{~N}\left(\mathrm{~V}_{4}\right)+45 \mathrm{~N}\left(\mathrm{~V}_{8}\right)$. Na segunda safra, o sistema plantio direto, novamente, proporcionou maior produtividade, porém manejado com $120 \mathrm{~N}$ (S). Na literatura, há trabalhos envolvendo análise econômica de doses de N (Aguiar et al. 2008),

Tabela 3. Produtividade e receita bruta obtidas com a cultura do milho, em função do manejo do solo e da adubação nitrogenada (Selvíria, MS, safras 2007/2008 e 2008/2009).

\begin{tabular}{cccccc}
\hline \multirow{2}{*}{$\begin{array}{c}\text { Manejo } \\
\text { do solo }\end{array}$} & $\begin{array}{c}\text { Manejo da adubação } \\
\text { nitrogenada }\end{array}$ & \multicolumn{2}{c}{ Produtividade $\left(\mathrm{sc} \mathrm{ha}^{-1}\right)$} & \multicolumn{2}{c}{ Receita Bruta $(\mathrm{R} \$)$} \\
\cline { 3 - 5 } & $\mathrm{Sem} \mathrm{N}$ & $2007 / 2008$ & $2008 / 2009$ & $2007 / 2008$ & $2008 / 2009$ \\
\hline \multirow{5}{*}{ Escarificador + niveladora } & $120 \mathrm{~N}(\mathrm{~S})$ & 111,6 & 104,8 & $2.008,21$ & $1.886,18$ \\
& $30 \mathrm{~N}(\mathrm{~S})+90 \mathrm{~N}\left(\mathrm{~V}_{6}\right)$ & 125,4 & 118,2 & $2.257,57$ & $2.128,07$ \\
& $\left.120 \mathrm{~N} \mathrm{V(})_{6}\right)$ & 115,6 & 109,2 & $2.080,52$ & $1.965,09$ \\
& $30 \mathrm{~N}(\mathrm{~S})+45 \mathrm{~N}\left(\mathrm{~V}_{4}\right)+45 \mathrm{~N}\left(\mathrm{~V}_{8}\right)$ & 130,8 & 111,1 & $2.355,28$ & $2.000,26$ \\
\hline \multirow{5}{*}{ Grade pesada + niveladora } & $\mathrm{Sem} \mathrm{N}$ & 101,5 & 95,3 & $1.826,78$ & $1.714,69$ \\
& $120 \mathrm{~N}(\mathrm{~S})$ & 135,8 & 120,5 & $2.445,27$ & $2.168,63$ \\
& $30 \mathrm{~N}(\mathrm{~S})+90 \mathrm{~N}\left(\mathrm{~V}_{6}\right)$ & 117,9 & 125,3 & $2.122,03$ & $2.255,75$ \\
& $\left.120 \mathrm{~N} \mathrm{V(}()_{6}\right)$ & 116,8 & 120,6 & $2.102,95$ & $2.170,65$ \\
& $30 \mathrm{~N}(\mathrm{~S})+45 \mathrm{~N}\left(\mathrm{~V}_{4}\right)+45 \mathrm{~N}\left(\mathrm{~V}_{8}\right)$ & 124,9 & 101,1 & $2.248,73$ & $1.819,63$ \\
\hline \multirow{5}{*}{ Sistema plantio direto } & $\mathrm{Sem} \mathrm{N}$ & 111,2 & 85,9 & $2.001,71$ & $1.545,53$ \\
& $120 \mathrm{~N}(\mathrm{~S})$ & 131,8 & 136,9 & $2.373,26$ & $2.464,67$ \\
& $30 \mathrm{~N}(\mathrm{~S})+90 \mathrm{~N}\left(\mathrm{~V}_{6}\right)$ & 128,4 & 130,4 & $2.311,34$ & $2.348,09$ \\
& $120 \mathrm{~N} \mathrm{~V}\left({ }_{6}\right)$ & 131,3 & 130,8 & $2.363,04$ & $2.353,52$ \\
& $30 \mathrm{~N}(\mathrm{~S})+45 \mathrm{~N}\left(\mathrm{~V}_{4}\right)+45 \mathrm{~N}\left(\mathrm{~V}_{8}\right)$ & 146,1 & 135,2 & $2.630,12$ & $2.433,52$ \\
\hline
\end{tabular}


mas não foi possível localizar trabalhos que fizessem uma comparação econômica, envolvendo o modo de aplicação do nitrogênio na cultura do milho.

$\mathrm{Na}$ Tabela 3, encontram-se os valores referentes às receitas brutas por hectare, obtidas nas combinações dos tratamentos para o milho, nas duas safras de cultivo. Sendo constante o preço do milho, as receitas brutas dos tratamentos seguem a mesma tendência das produtividades (Tabela 3).

Os valores referentes ao lucro operacional, para cada tratamento estudado, encontram-se na Tabela 4. Na safra 2007/2008, o lucro operacional foi negativo (houve prejuízo) para todos os tratamentos em que houve manejo do solo com escarificador + niveladora e para a maioria dos tratamentos com manejo do solo efetuado por grade pesada + niveladora. Por outro lado, houve efeito positivo do sistema plantio direto, havendo, assim, lucratividade neste tipo de manejo do solo, quando se fez a adubação nitrogenada. Aguiar et al. (2008), avaliando o efeito de diferentes práticas culturais envolvendo sistemas de manejo de solo, com utilização de plantas de cobertura, híbridos de milho e doses de $\mathrm{N}$ em cobertura, na região de Goiânia (GO), verificaram efeito positivo do milho comercializado em abril de 2007, cultivado em sistema plantio direto sob pousio, sem adubação nitrogenada, diferenciando-se, parcialmente, do que foi observado neste trabalho.
Observa-se (Tabela 4), também, que a combinação do sistema plantio direto com a aplicação de $30 \mathrm{~kg} \mathrm{ha}^{-1} \mathrm{de} \mathrm{N}$, na ocasião da semeadura, e $45 \mathrm{~kg} \mathrm{ha}^{-1}$ em $\mathrm{V}_{4}+45 \mathrm{~kg} \mathrm{ha}^{-1}$ em $\mathrm{V}_{8}$ promoveu o maior lucro operacional na safra 2007/2008. Na safra 2008/2009, o maior valor foi observado no sistema plantio direto, associado à aplicação antecipada de todo o $\mathrm{N}(120 \mathrm{~N}(\mathrm{~S}))$.

$\mathrm{Na}$ Tabela 4, encontram-se os valores referentes ao índice de lucratividade, acompanhando a mesma tendência do lucro operacional. Os tratamentos que envolveram o manejo do solo com escarificador + niveladora proporcionaram índice de lucratividade negativo, independentemente do manejo de $\mathrm{N}$ adotado, assim como nas áreas em que o preparo do solo ocorreu com grade pesada + niveladora, com exceção do manejo antecipado do nitrogênio, logo após a semeadura, na safra 2007/2008. O sistema plantio direto proporcionou os maiores índices de lucratividade, em ambas as safras. No entanto, Rapassi et al. (2003), comparando, economicamente, o sistema plantio direto, em relação ao preparo de solo convencional (aração + gradagem pesada + gradagem niveladora), no feijoeiro de inverno irrigado, verificaram que o índice de lucratividade foi maior com o manejo do solo com grade aradora e niveladora (preparo convencional).

Em relação à produtividade de equilíbrio (produtividade mínima para cobrir os custos), é

Tabela 4. Lucro operacional (LO), por hectare, e índice de lucratividade (IL) obtidos com a cultura do milho, em função do manejo do solo e da adubação nitrogenada (Selvíria, MS, safras 2007/2008 e 2008/2009).

\begin{tabular}{ccrrrr}
\hline \multirow{2}{*}{$\begin{array}{c}\text { Manejo } \\
\text { do solo }\end{array}$} & $\begin{array}{c}\text { Manejo da adubação } \\
\text { nitrogenada }\end{array}$ & \multicolumn{2}{c}{ LO (R\$) } & \multicolumn{2}{c}{ IL (\%) } \\
\cline { 3 - 5 } & $\mathrm{Sem} \mathrm{N}$ & $-2007 / 2008$ & $2008 / 2009$ & $2007 / 2008$ & $2008 / 2009$ \\
\hline \multirow{5}{*}{ Escarificador + niveladora } & $120 \mathrm{~N}(\mathrm{~S})$ & $-389,56$ & $-350,15$ & $-14,24$ & $-16,82$ \\
& $30 \mathrm{~N}(\mathrm{~S})+90 \mathrm{~N}\left(\mathrm{~V}_{6}\right)$ & $-140,20$ & $-269,70$ & $-16,25$ & $-21,34$ \\
& $120 \mathrm{~N} \mathrm{~V}\left({ }_{6}\right)$ & $-317,25$ & $-432,68$ & $-13,23$ & $-11,25$ \\
& $30 \mathrm{~N}(\mathrm{~S})+45 \mathrm{~N}\left(\mathrm{~V}_{4}\right)+45 \mathrm{~N}\left(\mathrm{~V}_{8}\right)$ & $-80,30$ & $-435,32$ & $-3,30$ & $-17,05$ \\
\hline \multirow{5}{*}{ Grade pesada + niveladora } & $\mathrm{Sem} \mathrm{N}$ & $-116,95$ & $-229,04$ & $-6,02$ & $-11,78$ \\
& $120 \mathrm{~N}(\mathrm{~S})$ & 185,76 & $-90,88$ & 8,22 & $-4,02$ \\
& $30 \mathrm{~N}(\mathrm{~S})+90 \mathrm{~N}\left(\mathrm{~V}_{6}\right)$ & $-137,48$ & $-3,76$ & $-6,08$ & $-0,17$ \\
& $\left.120 \mathrm{~N} \mathrm{V(}{ }_{6}\right)$ & $-156,56$ & $-88,86$ & $-6,93$ & $-3,93$ \\
& $30 \mathrm{~N}(\mathrm{~S})+45 \mathrm{~N}\left(\mathrm{~V}_{4}\right)+45 \mathrm{~N}\left(\mathrm{~V}_{8}\right)$ & $-39,92$ & $-469,01$ & $-1,74$ & $-20,49$ \\
\hline \multirow{5}{*}{ Sistema plantio direto } & $\mathrm{Sem} \mathrm{N}$ & 19,20 & $-436,97$ & 0,97 & $-22,04$ \\
& $120 \mathrm{~N}(\mathrm{~S})$ & 74,97 & 166,39 & 3,26 & 7,24 \\
& $30 \mathrm{~N}(\mathrm{~S})+90 \mathrm{~N}\left(\mathrm{~V}_{6}\right)$ & 13,06 & 49,80 & 0,57 & 2,17 \\
& $120 \mathrm{~N} \mathrm{~V}\left({ }_{6}\right)$ & 64,76 & 55,24 & 2,82 & 2,40 \\
& $30 \mathrm{~N}(\mathrm{~S})+45 \mathrm{~N}\left(\mathrm{~V}_{4}\right)+45 \mathrm{~N}\left(\mathrm{~V}_{8}\right)$ & 294,03 & 97,43 & 12,59 & 4,17 \\
\hline
\end{tabular}


possível verificar, na Tabela 5, que, para o preço de $\mathrm{R} \$ 18,00$ por saca de $60 \mathrm{~kg}$ de milho, o manejo envolvendo escarificador + niveladora e com aplicação de $30 \mathrm{~kg} \mathrm{ha}^{-1}$ de $\mathrm{N}$, na ocasião da semeadura, e $45 \mathrm{~kg} \mathrm{ha}^{-1} \mathrm{em} \mathrm{V}_{4}+45 \mathrm{~kg} \mathrm{ha}^{-1} \mathrm{em} \mathrm{V}_{8}$ precisou de maior produtividade de equilíbrio, sendo esta de 135,3 sc por hectare. O manejo do solo com grade pesada + niveladora, sem aplicação de adubo nitrogenado, precisa da menor produtividade de equilíbrio, sendo, esta, de 108 sc por hectare, para cobrir os custos de produção. Porém, o não fornecimento de N, em solos cultivados, pode acarretar a diminuição dos seus teores, ao longo dos anos, comprometendo, assim, o sucesso da atividade, ao longo do tempo, caso não haja reposição do nutriente. Para Tsunechiro (2008), a produtividade de equilíbrio foi de 68 sacas por hectare $(38 \%$ menor que o tratamento grade pesada + niveladora, sem aplicação de adubo nitrogenado, e 49,7\% menor que o tratamento utilizando escarificador + niveladora, com aplicação de $30 \mathrm{~kg} \mathrm{ha}^{-1} \mathrm{de} \mathrm{N}$, na ocasião da semeadura, e $45 \mathrm{~kg} \mathrm{ha}^{-1} \mathrm{em} \mathrm{V}_{4}+45 \mathrm{~kg} \mathrm{ha}^{-1} \mathrm{em}$ $\mathrm{V}_{8}$ ). Entretanto, na região dos Chapadões (safra 2009/2010), a produtividade de equilíbrio, para o valor de R \$ 12,81 por saca de $60 \mathrm{~kg}$ de grãos, é de 158 sacas por hectare (Kaneko \& Leal 2010), evidenciando, dessa maneira, grande oscilação entre preços e produtividades das regiões produtoras de milho, em função das safras agrícolas.
Na Tabela 5, encontram-se os valores (em R\$) da saca de $60 \mathrm{~kg}$ de milho, para o preço de equilíbrio (preço mínimo para cobrir o COT). Os grãos produzidos no sistema plantio direto, com adubação nitrogenada, obtiveram menor preço de equilíbrio, quando comparados aos produzidos nos outros tipos de manejo do solo. Em relação ao manejo do nitrogênio, houve muita variação entre os preços de equilíbrio, ressaltando, assim, a importância de novos estudos de análise de custo e rentabilidade, englobando a adubação nitrogenada. Para Kaneko et al. (2007), o preço de equilíbrio da saca de milho foi de R\$ 14,59 , ou seja, $8,75 \%$ menor que o valor encontrado para o manejo do solo com sistema plantio direto manejado com $30 \mathrm{~N}(\mathrm{~S})+45 \mathrm{~N}\left(\mathrm{~V}_{4}\right)+45 \mathrm{~N}\left(\mathrm{~V}_{8}\right)$, na safra 2007/2008.

\section{CONCLUSÃO}

O solo manejado com sistema plantio direto, após 11 anos de implantação, proporcionou maior produtividade de grãos e rentabilidade, quando comparado ao manejo com grade pesada + niveladora e com escarificador + niveladora. Ademais, o manejo com o sistema plantio direto, associado à adubação nitrogenada, promoveu índice de lucratividade e lucro operacional positivos, nos dois anos agrícolas de cultivo, evidenciando, assim, efeito favorável ao uso destas práticas, por parte dos agricultores.

Tabela 5. Produtividade e preço de equilíbrio obtidos com a cultura do milho, em função do manejo do solo e da adubação nitrogenada (Selvíria, MS, safras 2007/2008 e 2008/2009).

\begin{tabular}{|c|c|c|c|c|c|}
\hline \multirow{2}{*}{$\begin{array}{l}\text { Manejo } \\
\text { do solo }\end{array}$} & \multirow{2}{*}{$\begin{array}{l}\text { Manejo da adubação } \\
\text { nitrogenada }\end{array}$} & \multicolumn{2}{|c|}{$\begin{array}{l}\text { Produtividade de equilíbrio } \\
\qquad\left(\mathrm{sc} \mathrm{ha}^{-1}\right)\end{array}$} & \multicolumn{2}{|c|}{$\begin{array}{l}\text { Preço de equilíbrio } \\
\left(\mathrm{R} \$ \mathrm{sc}^{-1}\right)\end{array}$} \\
\hline & & $2007 / 2009$ & $2008 / 2009$ & $2007 / 2009$ & $2008 / 2009$ \\
\hline \multirow{5}{*}{ Escarificador + niveladora } & Sem N & 115,7 & 115,7 & 20,99 & 21,64 \\
\hline & $120 \mathrm{~N}(\mathrm{~S})$ & 133,2 & 133,2 & 21,49 & 22,88 \\
\hline & $30 \mathrm{~N}(\mathrm{~S})+90 \mathrm{~N}\left(\mathrm{~V}_{6}\right)$ & 133,2 & 133,2 & 19,12 & 20,28 \\
\hline & $120 \mathrm{~N} \mathrm{V(})$ & 133,2 & 133,2 & 20,74 & 21,96 \\
\hline & $30 \mathrm{~N}(\mathrm{~S})+45 \mathrm{~N}\left(\mathrm{~V}_{4}\right)^{6}+45 \mathrm{~N}\left(\mathrm{~V}_{8}\right)$ & 135,3 & 135,3 & 18,61 & 21,92 \\
\hline \multirow{5}{*}{ Grade pesada + niveladora } & Sem N & 108,0 & 108,0 & 19,15 & 20,40 \\
\hline & $120 \mathrm{~N}(\mathrm{~S})$ & 125,5 & 125,5 & 16,63 & 18,75 \\
\hline & $30 \mathrm{~N}(\mathrm{~S})+90 \mathrm{~N}\left(\mathrm{~V}_{6}\right)$ & 125,5 & 125,5 & 19,17 & 18,03 \\
\hline & $120 \mathrm{~N} \mathrm{~V}(6)$ & 125,5 & 125,5 & 19,34 & 18,74 \\
\hline & $30 \mathrm{~N}(\mathrm{~S})+45 \mathrm{~N}\left(\mathrm{~V}_{4}\right)+45 \mathrm{~N}\left(\mathrm{~V}_{8}\right)$ & 127,1 & 127,1 & 18,32 & 22,64 \\
\hline \multirow{5}{*}{ Sistema plantio direto } & Sem N & 110,1 & 110,1 & 17,83 & 23,09 \\
\hline & $120 \mathrm{~N}(\mathrm{~S})$ & 127,7 & 127,7 & 17,43 & 16,78 \\
\hline & $30 \mathrm{~N}(\mathrm{~S})+90 \mathrm{~N}\left(\mathrm{~V}_{6}\right)$ & 127,7 & 127,7 & 17,90 & 17,62 \\
\hline & $120 \mathrm{~N} \mathrm{~V}(6)$ & 127,7 & 127,7 & 17,51 & 17,58 \\
\hline & $30 \mathrm{~N}(\mathrm{~S})+45 \mathrm{~N}\left(\mathrm{~V}_{4}\right)+45 \mathrm{~N}\left(\mathrm{~V}_{8}\right)$ & 129,8 & 129,8 & 15,99 & 17,28 \\
\hline
\end{tabular}




\section{AGRADECIMENTOS}

Agradecemos à Fundação de Amparo à Pesquisa do Estado de São Paulo (FAPESP), pela bolsa de mestrado concedida a Flávio Hiroshi Kaneko.

\section{REFERÊNCIAS}

AGUIAR, R. A. et al. Análise econômica de diferentes práticas culturais na cultura do milho (Zea mays L.). Pesquisa Agropecuária Tropical, Goiânia, v. 38, n. 4, p. 241-248, 2008.

BRASIL. Ministério da Agricultura, Pecuária e Abastecimento. Agricultura brasileira em números. 2009. Disponível em: <www.agricultura.gov.br $>$. Acesso em: 05 maio 2009.

CANTARELLA, H.; DUARTE, A. P. Manejo da fertilidade do solo para a cultura do milho. In: GALVÃO, J. C. C.; MIRANDA, G. V. Tecnologias de produção do milho. Viçosa: UFV, 2004. p. 139-182.

EMPRESA BRASILEIRA DE PESQUISA AGROPECUÁRIA (Embrapa). Sistema brasileiro de classificação de solo. Rio de Janeiro: Embrapa/CNPS, 1999.

FEDERAÇÃO BRASILEIRA DE PLANTIO NA PALHA (Febrapdp). Evolução da área de plantio direto no Brasil. Disponível em: $<w w w . a g r i . c o m . b r / f e b r a p d p>$. Acesso em: 05 maio de 2009.

FIGUEIREDO, C. C. et al. Sistemas de manejo na absorção de nitrogênio pelo milho em um Latossolo vermelho no Cerrado. Pesquisa Agropecuária Brasileira, Brasília, DF, v. 40, n. 3, p. 279-287, 2005.

KANEKO, F. H. et al. Análise econômica da cultura do milho considerando a viabilidade ou não do armazenamento dos grãos da safra 2006/07. In: SIMPÓSIO INTERNACIONAL DE INICIAÇ̃̃O CIENTÍFICA DA UNIVERSIDADE DE SÃO PAULO, 15., 2007, Pirassununga. Anais... Pirassununga: USP, 2007. 1 CD-ROM.
KANEKO, F. H.; LEAL, A. J. F. Estimativa do custo de produção da cultura do milho na região dos Chapadões, safra 2009/10. Pesquisa - Tecnologia - Produtividade, Chapadão do Sul, v. 3, n. 1, p. 128-134, 2010.

MARTIN, N. B. et al. Sistema integrado de custos agropecuários - "Custagri”. Informações Econômicas, São Paulo, v. 28, n. 1, p. 4-7, 1997.

MATSUNAGA, M. et al. Metodologia de custo de produção utilizada pelo IEA. Agricultura em São Paulo, São Paulo, v. 23, n. 1, p. 123-139, 1976.

MELO FILHO, G. A. Custos: plantio direto x plantio convencional. Brasília, DF: APDC/Febrapdp, 2000.

RAPASSI, R. M. et al. Análise econômica comparativa após um ano de cultivo do feijoeiro de inverno, em sistemas de plantio convencional e direto, com diferentes fontes e doses de nitrogênio. Bragantia, Campinas, v. 62, n. 3, p. 397-404, 2003.

SANTOS, H. P.; LHAMBY, J. C. B.; SPERA, S. T. Rendimento de grãos de soja em função de diferentes sistemas de manejos de solo e de rotação de culturas. Ciência Rural, Santa Maria, v. 36, n. 1, p. 21-29, 2006.

SANTOS, H. P.; TOMM, G. O.; KOCHHANN, R. A. Rendimento de grãos de milho em função de diferentes sistemas de manejo de solo e de rotação de culturas. Revista Brasileira de Agrociência, Pelotas, v. 9, n. 3, p. 251-256, 2003.

TSUNECHIRO, A. Milho e soja: custo de produção e rentabilidade na safra 2003/04. Disponível em: <www. iea.sp.gov.br>. Acesso em 19 jan. 2008.

VASCONCELOS, R. C. et al. Estimativa dos custos de produção de milho na safra agrícola 1998/1999 no município de Lavras - MG. Ciências Agrotecnológicas, Lavras, v. 26, n. 2, p. 283-291, 2002. 